\title{
Exposure to Cigarette Smoke Contributes to the Risk of Developing a Colorectal Adenoma, Doesn't It? Are Repeated Exposures to Such Smoke Dangerous?
}

\author{
Bong Hwa Lee, Min Jung Kim, Hyoung Chul Park \\ Department of Surgery, Hallym University College of Medicine, Anyang, Korea
}

See Article on Page 51-57

One cigarette contains over 600 ingredients, 4,000 chemicals, 50 cancer-causing agents and many poisonous toxins. In the early 1990s, Zahm et al. [1] of the National Cancer Institute, in a study that used flexible sigmoidoscopy to examine 185 nonsmokers, 229 ex-smokers, and 132 current smokers, reported respective risk ratios for developing adenomatous polyps of 1.0, 1.2, and 2.7. Standardized prevalence rates for polyps increased by smoking category (never smoked: 0.094, ex-smoker: 0.118, current smokers: 0.214 ). Both adenomatous and hyperplastic polyps showed an association with pack years among both current and ex-smokers. In a meta-analysis of 42 independent observational studies up to 2007 [2], the pooled risks estimated for current and former smokers and those who had always smokers in comparison with those who had never smoked were 2.14 (95\% confidence interval [CI], $1.86-2.46), 1.47$, and 1.82 , respectively. The study provided strong evidence for the detrimental effect of cigarette smoking on the development of adenomatous polyps.

Because the risk for developing an adenoma was greater, smoking may be important for both the formation and aggressiveness of adenomas. Anderson et al. [3] screened 600 patient who had high-definition wide-angle colonoscopes. Smoking was associated with having a flat adenoma of any size (adjusted odds ratio, 2.53). Figueiredo et al. [4] conducted a combined analysis of the occurrences of conventional adenomas and serrated polyps by using individual-level data from 2,915 patients participating in three

Correspondence to: Bong Hwa Lee, M.D.

Department of Surgery, Hallym University Sacred Heart Hospital, 22 Gwanpyeong-ro 170beon-gil, Dongan-gu, Anyang 14068, Korea

Tel: +82-31-380-3772, Fax: +82-31-380-4118,

E-mail: bshlee@hallym.ac.kr

(c) 2016 The Korean Society of Coloproctology

This is an open-access article distributed under the terms of the Creative Commons Attribution NonCommercial License (http://creativecommons.org/licenses/by-nc/4.0) which permits unrestricted noncommercial use, distribution, and reproduction in any medium, provided the original work is properly cited. colonoscopy-based clinical trials. Cigarette smoking had only a weak association with adenomas, but was associated with a significantly increased risk of developing serrated polyps, particularly in the left colorectum.

The association between cigarette smoking and the risk of developing colorectal cancer in a large prospective cohort from the United States was reported in 2009 [5]. In that prospective study of 184,187 people, the incidence of colorectal cancer was significantly higher in current (hazard ratios [HR], 1.27) and former smokers (HR, 1.23) than it was in lifelong nonsmokers (Table 1). The relative risk was greatest among current smokers with at least 50 years of smoking (HR, 1.38; 95\% CI, 1.04-1.84). Among former smokers, the risk of colorectal cancer decreased with greater time since cessation $(\mathrm{P}=0.0003)$ and with earlier age at cessation $(\mathrm{P}=0.0014)$. No association was seen among former smokers who had quit before the age of 40 years or had abstained for 31 years or more.

Liu et al. [6] investigated the effects of exposure to cigarette smoke (CS) on inflammation-associated tumorigenesis in the $\mathrm{balb} / \mathrm{c}$ mice. During exposure to smoke exposure, the mice were put into a ventilated smoking chamber $\left(39.0 \times 23.5 \times 21.0 \mathrm{~cm}^{3}\right)$ with $2 \% \mathrm{CS}$ (v/v, smoke/air). The smoke/air concentration in the chamber was kept constant by the use of peristaltic pumps (Masterflex, Cole Parmer Instrument, Niles, IL, USA), which delivered smoke. Cigarette smoking significantly attenuated the apoptotic effect probably via the induction of antiapoptotic protein bcl-2. Vascular endothelial growth factor and angiogenesis in the colon were also increased in animals with colitis that had been exposed to CS.

On the basis of the references mentioned above, the readers have to figure out carefully the purpose of this article, "Association Between Exposure to Environmental Tobacco Smoke at the Workplace and Risk of Developing a Colorectal Adenoma: A Cross-Sectional Study," published in this issue [7]. In that research, patients in the nonadenoma group were compared with those in the colorectal adenoma group by using the variables of passive smoking. As a result of that comparison, the fully-adjusted 
Table 1. Hazard ratios for patients with colorectal cancer caused by cigarette smoking among current and former smokers compared with those who had never smoked (CPS-III nutrition cohort 19922005)

\begin{tabular}{lccc}
\hline Smoking & All & Men & Women \\
\hline Never smoked & 1.00 & 1.00 & 1.00 \\
Former smoker & 1.23 & 1.26 & 1.19 \\
Current smoker & 1.27 & 1.24 & 1.30 \\
\hline
\end{tabular}

odd ratio for developing a colorectal adenoma as a result of exposure to environmental tobacco smoke was 1.95 (95\% CI, 1.082.44). The article is encouraging in that it provides evidence to support further study of the effects of environmental hazards on the risks for developing colorectal cancer in this country. Various approaches to one subject can be inspiring in many different ways.

\section{CONFLICT OF INTEREST}

No potential conflict of interest relevant to this article was reported.

\section{REFERENCES}

1. Zahm SH, Cocco P, Blair A. Tobacco smoking as a risk factor for colon polyps. Am J Public Health 1991;81:846-9.

2. Botteri E, Iodice S, Raimondi S, Maisonneuve P, Lowenfels AB. Cigarette smoking and adenomatous polyps: a meta-analysis. Gastroenterology 2008;134:388-95.

3. Anderson JC, Stein B, Kahi CJ, Rajapakse R, Walker G, Alpern Z. Association of smoking and flat adenomas: results from an asymptomatic population screened with a high-definition colonoscope. Gastrointest Endosc 2010;71:1234-40.

4. Figueiredo JC, Crockett SD, Snover DC, Morris CB, McKeownEyssen G, Sandler RS, et al. Smoking-associated risks of conventional adenomas and serrated polyps in the colorectum. Cancer Causes Control 2015;26:377-86.

5. Hannan LM, Jacobs EJ, Thun MJ. The association between cigarette smoking and risk of colorectal cancer in a large prospective cohort from the United States. Cancer Epidemiol Biomarkers Prev 2009;18:3362-7.

6. Liu ES, Ye YN, Shin VY, Yuen ST, Leung SY, Wong BC, et al. Cigarette smoke exposure increases ulcerative colitis-associated colonic adenoma formation in mice. Carcinogenesis 2003;24:140713.

7. Lee SH, Hong JY, Lee JU, Lee DR. Association between exposure to environmental tobacco smoke at the workplace and risk for developing a colorectal adenoma: a cross-sectional study. Ann Coloproctol 2016;32:51-7. 